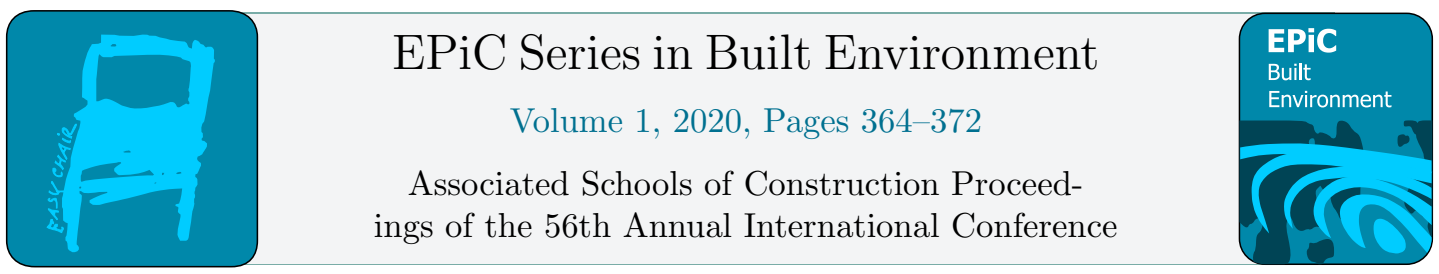

\title{
Strategies to Increase the Adoption Rate of Lean Construction
}

\author{
Zhili Gao, Ph.D., Mughees Aslam, and Gary Smith, Ph.D. \\ North Dakota State University \\ Fargo, North Dakota
}

\begin{abstract}
Despite its enormous potentials for increasing efficiencies of the construction process, lean Construction (LC) has not been adopted into the majority of the construction industry yet. Furthermore, barriers and strategies for implementing LC have not been adequately studied by past and current research that can lead to the rapid uptake of LC within the construction industry. This study is to identify barriers that are hindering the construction industry to adopt LC and to further recommend suitable measures to overcome these barriers. In this study, a systematic literature review was carried out by reviewing theoretical/analytic papers, case studies and conceptual papers on the subject. After careful examination, eighty-seven (87) papers are kept for further analysis. Analysis indicated that approximately $80 \%$ of existing research studies are focused on identifying the implementation barriers only, whereas only $20 \%$, presented barriers that hinder the adoption of LC. As a result, fifty-eight (58) barriers towards adopting LC and sixty-nine (69) strategies to overcome them were identified and classified under three population groups within the construction industry, based on their familiarity and implementation level of LC. The outcome of this study will potentially assist the construction industry in taking measures for increasing awareness and boosting the adoption rate of LC, along with the successful implementation of this innovative change management philosophy that ultimately will lead to optimized construction solutions.
\end{abstract}

Key Words: Lean Construction, Barriers, Strategies, Implementation, Adoption rate

\section{Introduction}

Lean construction (LC) was developed to optimize the construction process by removing inefficiencies and waste from existing management practices. Over the last few decades, the construction industry has experienced some successful implementations of LC which resulted in cost and time savings, as well as productivity enhancement. However, despite its promise and benefits, still the required uptake of LC is very sparse within the construction industry (Noor et al., 2018; Babalola et al., 2018; Bashir et al., 2015; Wandahl, 2014). According to McGrawHill (2013), out of a sample of 194, $48 \%$ were still not familiar with the broad overarching concepts of LC. Similarly, $51 \%$

T. Leathem (ed.), ASC 2020 (EPiC Series in Built Environment, vol. 1), pp. 364-372 
of the representatives have not used LC either because of unfamiliarity (22\%) or even with familiarity (29\%) of lean concepts. Similarly, Balabola et al. (2018) found that although the awareness for LC is increasing, still more than 50\% (out of data sample of 446) are not aware of LC. In order to increase the adoption rate of $\mathrm{LC}$, it is imperative to identify barriers hindering the construction industry for using LC. LC adoption barriers prevent the construction industry in using the LC practices because of three major reasons as (1) Unawareness about LC, (2) lack of confidence or fear for implementation and (3) implementation barriers that are hindering LC for performing to its full potential (Olamilokun, 2015; Ballard and Kim, 2007; Arbulu, 2006). However, the dilemma is that most of the research in identifying barriers and successful implementation factors are tilted towards the implementation of LC in activities or projects (Reason 3 as mentioned above). Whereas very little research is carried out in identifying the overall barriers and strategies that are hindering the construction industry for adopting LC. Although few researchers like Mossman (2009), Babalola et al. (2018), and Bashir et al (2015) endeavored to identify barriers that prevented the CI for using LC but fell short in explaining the strategies with respect to each identified barrier. In order to achieve success, a more practical approach would be to identify barriers along with respective strategies to overcome those barriers

In order to fill gaps as discussed above, this study identified barriers along with recommended strategies to overcome the effect of barriers by considering three types of populations within the construction industry that are adversely contributing towards lean adoption: First group (majority) includes those who are not even aware of LC, second group includes those who are familiar with LC but don't want to implement it, and last group involves lean practitioners who implement LC but could not achieve significant successes and later on refrain from using lean practices any further. Lack of adequate awareness has been identified as one of the significant barriers for adopting LC by many researchers (Noor et al., 2018, Sarhan, 2011; Simonsen et al., 2014; Jørgensen and Emmitt, 2008). Similarly, others have identified fear of failures or uncertainties associated with LC that is preventing the construction industry from adopting lean practices (Abdullah et al., 2009; Mossman, 2009; Warcup, 2015). Many lean practitioners have identified wrong or partial implementation (Mossman, 2009; Porwal et al., 2010) and lack of cultural acceptance for lean (Shang and Sui Pheng, 2014) as main barriers which can result in failures of lean effort. These have identified a series of barriers but couldn't present suitable actions to be taken by the constructors to overcome them. Resultantly, construction companies remain either unaware of this management philosophy or are hesitant of actual adopting them. This is a novel study in which a comprehensive tactical plan is presented to overcome barriers associated with successful LC implementation with respect to three population groups as discussed above. The outcomes of this study will be of great value for constructors who want to be benefitted by implementing LC tools and techniques successfully. Moreover, the results of this study can be helpful in nurturing the concept of LC in the construction industry.

\section{Methodology}

An extensive literature review is carried out to identify barriers associated with the adoption of LC and strategies to overcome the effects of these barriers. The literature review is organized into two stages: (1) Preliminary literature review and (2) detailed literature review. A preliminary literature review is carried out to establish gaps and develop the context of this study; additionally, a detailed literature review is conducted to achieve the objectives of this study. Theoretical papers, case studies, review papers and conceptual papers were reviewed from journals and applied databases, such as International Group for LC (IGLC), LCI, Elsevier, Science direct, Taylor \& Francis Online, American Society of Civil Engineers (ASCE) Library, and others. These data sources cover the theory and implementation of LC, lean tools and techniques, barriers in adopting LC and strategies to overcome 
these barriers. A three-stage strategy was adopted for the literature search as explained by Mok et al (2015). In the first stage of this study, 204 related articles were identified by going through the title as per the context of this study. During the second stage, further filtration was carried out to identify 124 articles that have a direct impact in the outcome of this study by going through abstracts and conclusions of all papers. In the last stage, 87 articles that have explained barriers and successful adopting strategies for LC were kept for further analysis. The complete schematic explanation of the methodology is showed in Figure 1.

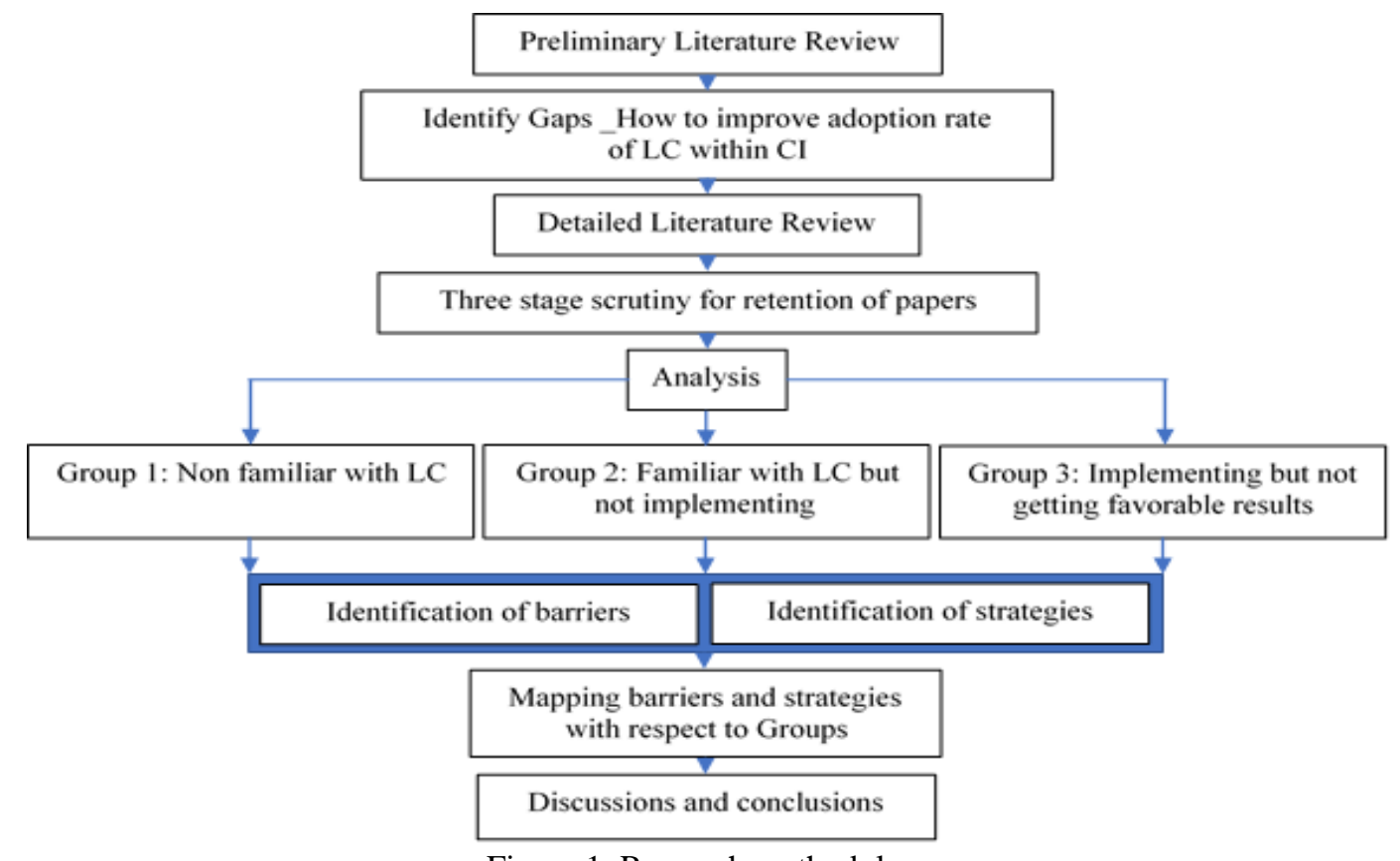

Figure 1. Research methodology

\section{Key findings}

After going through eighty-seven (87) articles, it was established that most of the research in identifying the barriers and strategies are carried out in isolation. As shown in Figure 2, 37\% of 87 articles have only identified the barriers, whereas $45 \%$ of those have identified only implementing strategies for LC in some context. The rest of the $18 \%$ of articles presented both barriers and strategies simultaneously but were discussed separately; therefore, it was difficult to identify strategies that can be used for overcoming respective barriers.

Additionally, most of the research was carried out in identifying the implementation barriers of LC but few studies discussed the barriers associated with adoption of LC within the construction industry. Analysis result indicated that approximately $80 \%$ of the articles are focused on identifying the implementation barriers whereas the other $20 \%$ presented barriers hindering the adoption of LC. The analysis result confirmed that the objective of this study mentioned early is sound and valid for the need of the construction industry.

\section{Barriers for adopting $L C$}


The explored barriers for adopting the LC were categorized based on three population groups discussed in the introduction section. Due to the limitation of the paper length, the detailed fifty-eight (58) barriers are not fully shown here; rather, a summary of top barriers is presented as following:
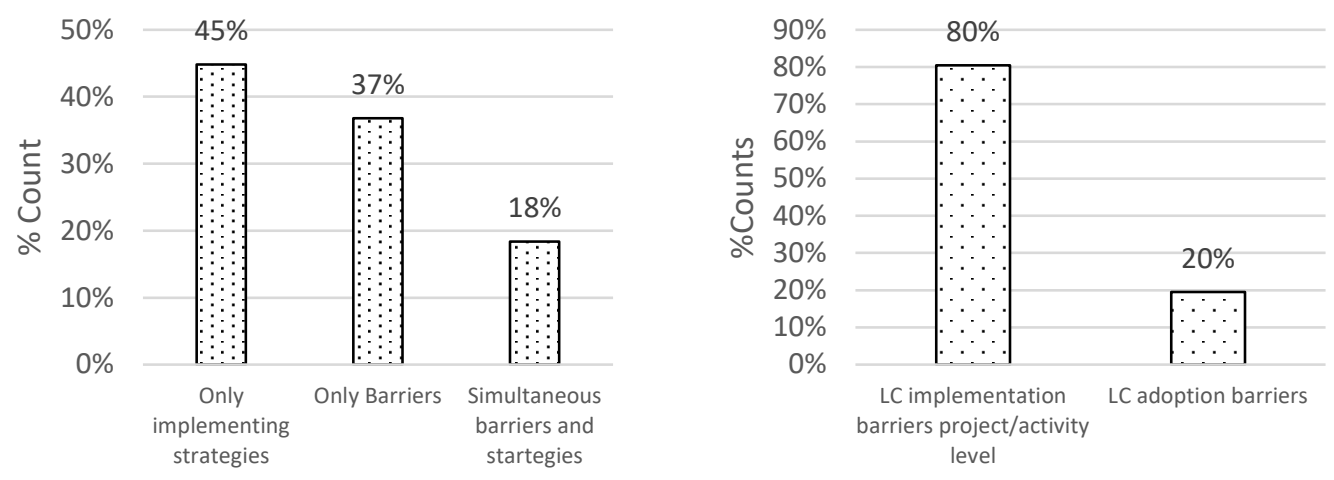

Figure 2: Statistics of existing research on LC implementing barriers vs. strategies

\section{Group 1: Unfamiliar with $L C$}

According to Jorgensen and Emmitt (2008), the construction industry is not comprehensively exposed to LC philosophies in comparison to the manufacturing industry. Sarhan and Fox (2013) conducted a questionnaire survey to determine the significant barriers and ended up with lacking adequate awareness and understanding of the lean concepts as the topmost barrier for implementing LC. Furthermore, authors suggested that discussing lean stories is a more formidable way of promoting the lean in construction than presenting the fanciful measured outcomes. According to McGraw Hill (2013), the dilemma is that construction companies consider existing management practices as flawless without estimating the amount of wastes generated during their implementation. Resultantly, these companies prefer to maintain the status quo and never try to indulge themselves in learning/implementing new management philosophies. The role of academic institutions and construction agencies in encouraging the innovative management techniques like LC is also very meager, thereby hindering the construction companies from adopting LC (Alinaitwe, 2009; Enshassi and Mohamed, 2019).

\section{Group 2: Familiar with LC but not implementing}

For the second group of practitioners, the issue is more likely to be fear of failures or uncertainties associated with adopting the new change on management concepts (Polat and Arditi, 2005; Mossman, 2009). It was found that the key stakeholders didn't want to change from existing practices and never engaged themselves in new risks that can potentially rise by implementing changes (Johansen, 2004; Simonsen, 2014). Similarly, they didn't want to use their resources in experimentations, considering LC practices too complex and challenging (Abdullah et al., 2009; Mossman, 2009; Warcup, 2015). Furthermore, Mosman (2009) reported that lean transformation time in construction can vary from at least 6 years to 16 years because of the fragmented nature of the construction projects. Group 2 population made their decision for not using the lean practices because of the prevalent myth that implementation time for lean tools and techniques is considerably long which can take them out of the competition (Marhani et al., 2013; Kawish, 2017; Bashir et al., 2015). Additionally, the cost of implementation of lean practices, often considered to be too high, was also hindering the construction 
companies for using lean concepts (Bashir et al., 2015). Resistance to change for LC has been identified as the topmost barriers by many authors (Bahidrah and Korkmaz, 2017; Steven, 2015). According to them, the highest resistance comes from employees and field management due to their lack of knowledge and understanding of lean concepts. Few organizations because of their failures in previous lean ventures refrain from using lean any further instead of evaluating the reasons for failures (Dehdasht and Zin, 2018)

\section{Group 3: Implementing LC but received unfavorable results}

Among the third population group, the need for implementation of lean in future projects diminished due to unfavorable results from (1) wrong or partial implementations (Warcup, 2015; Mossman, 2009; porwal et al., 2010), (2) poorly conceived lean concepts (Abdullah et al., 2009; Sarhan and Fox, 2013; Bashir et al., 2015; Ayarkwa et al., 2011; Alinaitwe, 2009; Mcgrwhill, 2013), (3) wrong selection of lean tools , (4) halfhearted implementation (Bashir et al., 2015), (5) lack of cultural acceptance for lean (Sarhan and Fox, 2012; Shang and Sui Pheng, 2014) and (6) low commitment from management (Abdullah et al., 2009; kawish, 2017; bashir et al., 2015; Mossman, 2009; Marhani et al., 2013). In addition, lack of adequate contractual agreement defining the relationships between different stakeholders also impeded the implementation process and normally perceived as the major factor in the failure of lean based initiatives in construction (Mossman, 2009). Resultantly, weak communication between owners, architects/engineers, contractors and even with subcontractors negatively affected the implementation process (Abdullah et al., 2009). Another big challenge associated with the implementation of LC was resistance from employees who treated it as the biggest threat in reducing their income (Bashir et al., 2015). According to Ballard et al. (2007), strong resistance to change from different stakeholders and lack of commitment and leadership were major barriers in implementing LC. One of the core principles of LC is looking for continuous improvement of the implementation process through effective evaluations. Presently, due to nonconformance to this principle, many companies failed to achieve the desired result as they never endeavored to improve the implementation process (Kanafani, 2015). Construction projects are heavily dependent upon external actors like subcontractors and suppliers for timely completion of specialty works and delivery of materials. However, non-involvement and support of external actors have been found to be the major cause for lean failures (Bashir et al 2015, Warcup, 2015).

\section{Strategies to overcome barriers}

The successful implementation of LC necessitates the removal of barriers as discussed above. These barriers will lead to identifying factors that can be crucial for the successful implementation of lean practice in construction. After establishing the barriers for adopting LC within all population groups, strategies to overcome these barriers are identified from the literature (Bashir et al., 2015; Shang and Sui Pheng, 2014; Ballard and kim, 2007; Enshassi et al., 2019; Warcup, 2015; Ayarkwa et al., 2011, Kawish, 2017; McGrawHill, 2013; Simonsen et al., 2014; Arbulu, 2016, Sarhan, 2011; Shou et al., 2016, Kanafani, 2015). The strategies for overcoming each barrier are independently investigated and are further lined up into the respective population group. Due to the limitation of the paper length, the detailed sixty-nine (69) strategies are not shown here; rather a summary of main strategies are listed below:

\section{Strategies for group 1}

- Publication and presenting lean results in massive construction forums.

- Introducing lean principles in the curriculum at the university and college level. 
- Convincing Owners for adopting LC for the added value to their projects.

- Informing organizations of the competitive advantage offered by LC over existing management techniques.

- Assisting Federal and state agencies in removing barriers hindering adoption of lean due to regulations, laws etc.

- Educating construction organizations about the wastes and inefficiencies using the existing management techniques in quantifiable terms.

Strategies for group 2

- Reduce fear/reservations by highlighting the positivity achieved through lean implementations.

- Analyze the approach towards lean rather than results, during initial applications. Start with belief on lean philosophies.

- Get help from external lean coaches/facilitator.

- Consistency and persistence to be shown by upper management for lean implementations.

- Use Computer modeling and simulation techniques to improve confidence.

- Get Owners to support lean application on their construction projects.

- Adopt a narrow and deep approach by ensuring smooth transition from existing practices to lean practices by following step by step implementation.

Strategies for group 3

- LC techniques should be gradually implemented.

- Hire external lean facilitators/consultants for training, planning, and implementation.

- Frequently measure the performance of lean tools and techniques and further evaluating the performance for optimization and learning.

- Develop an appropriate collaborative project delivery system for lean projects like Integrated project delivery or integrated form of agreement.

- Involve all project partners as early as possible especially during planning and design stages.

- Use building information modeling to facilitate lean implementation especially during planning and design sessions.

- Pre-qualify subcontractors and suppliers based on relationship, trust, and commitment for lean implementations.

- Select the most appropriate tools that are fully compatible with construction processes/activities.

\section{Discussion}

The main motivation for this study was to identify barriers that hinder the adoption of LC within the construction industry and recommending suitable strategies to overcome these barriers. Ten (10), twenty-one (21) and twenty-seven (27) barriers that are hindering three population groups 1, 2 and 3 for using LC are identified respectively. In order to overcome these barriers, eleven (11) strategies for group 1, twenty-three (23) strategies for group 2 and thirty-five (35) strategies for group 3 are identified. For group 1, major causes of non-familiarization with LC is either due to the fact that companies don't want to learn new innovative management techniques or there are not enough efforts made by lean promoters to reach out to them for promoting LC. The best strategy is to provide enough 
opportunities to the construction companies in the form of publications, conferences, congresses, workshops and extensive use of electronic media for getting acquainted with LC awareness.

For group 2, the major reasons for non-adaptation of LC are the fear of time/cost wastages if the implementation efforts fail, lack of confidence in LC, resistance to change from traditional approaches and cultural mismatch. More knowledge, training, and acquaintance with the benefits of LC can be a better way of building confidence in LC. For group 3, major reasons for noncompliance of LC tools and techniques are lack of knowledge, lack of effective training, non-compatibility of agreements/project delivery methods, wrong selection and implementation of lean tools and techniques. The best way to achieve perfection in implementing LC is to apply it gradually from one activity to another activity followed by rigorous evaluations of the complete implementation process.

Lean tools and techniques should be carefully selected based on their compatibility with construction processes. Collaboration through integrated project delivery coupled with improved visualization through Building Information Modelling (BIM) can be an effective way of implementing LC successfully. Adequate empowerment should be given to employees to make decisions in their area of expertise. The hallmark of LC is involving people especially downstream players as early as possible for collaborative decision making. Lookahead and monthly meetings are an effective platform to get input from employees. Subcontractors and suppliers are the key project participants who play a significant role in the successful implementation of LC. Their involvement during planning and design sessions can be very productive in maintaining a continuous flow of activities, information, and materials, reducing constructability issues, and adding value to the project. Training of subcontractors/suppliers along with other team members in understanding lean theories as well as its implementing protocols is key for the success of LC. The best way to plan, implement and train for LC is by utilizing services of external lean consultants who can guide especially newcomers for successful implementation of LC.

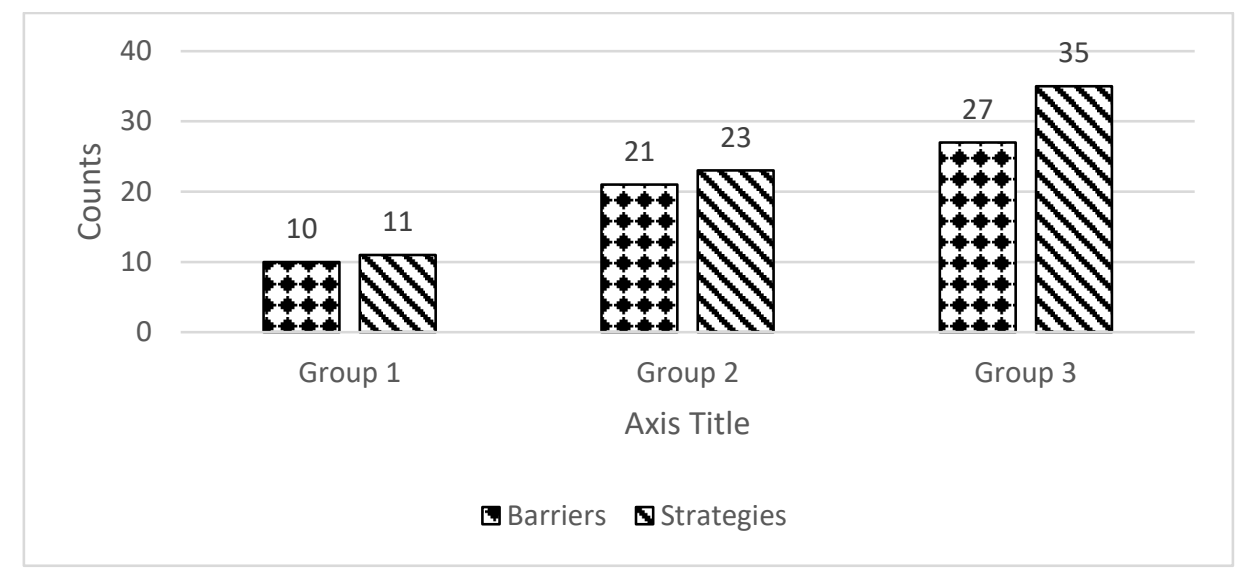

Figure 3: Summary- Identified Barriers and Strategies

\section{Conclusion}

According to Construction Industry Resources, LLC (CLMA, 2016), labor productivity of the construction industry has been stagnant since 1950 and below other industries. Traditional methods have not succeeded in the elimination of waste and non-value adding activities from construction processes, but they are the major reasons for the decline in productivity. The construction industry is 
looking forward to effective ways of reducing inefficiencies and wastes from construction to improve their productivity. $\mathrm{LC}$ so far has proved to be a reliable management philosophy to improve construction productivity and removing wastes from construction. However, the uptake of LC is quite low in the construction industry due to many barriers associated with different types of population groups. This study provided a comprehensive assessment of barriers and strategies to overcome these barriers through a detailed evaluation of the literature and case studies. The outcome of this study will provide a way forward to the construction industry in adopting and implementing LC. One practical implication of this study is that construction organizations, companies and clients can follow strategies as identified in this study for successfully implementing LC. Moreover, the construction industry can adopt measures for increasing awareness for LC and boosting the adoption rate of LC. This cyclic approach in which benefits of LC can be used as a foundation for taking such measures that will increase the awareness for LC. The theoretical implication is that this is a novel study in which barriers are identified based on population groups that are significantly hindering LC implementation and strategies are developed to overcome these barriers with respect to corresponding population groups. Consequently, the study will aid in raising the level of awareness of the professional body for adopting and then successfully implementing LC.

\section{References}

Abdullah, S., Abdul-Razak, A., Abubakar, A., \& Mohammad, I. S. (2009). Towards producing best practice in the Malaysian construction industry: the barriers in implementing the Lean Construction Approach. Faulty of Engineering and Geoinformation Science, Universiti Teknologi, Malaysia. https://www.researchgate.net/profile/Arman_Abdul_Razak/publication/202165546

Alinaitwe, H. M. (2009). Prioritizing Lean Construction Barriers in Uganda's Construction Industry. Journal of Construction in Developing Countries, 14(1).

Arbulu, R. 2006, 'Application of PULL and CONWIP in Construction Production Systems' In proceedings of the 14th Annual Conference of the International Group for Lean Construction, IGLC, Santiago, Chile, 215-226.

Ayarkwa, J., Agyekum, K., \& Adinyira, E. (2011). "Barriers to sustainable implementation of lean construction in the Ghanaian building industry." Proceedings 6th Built Environment Conference, JHB, South Africa ISBN: 978-0-86970-713-5.

Babalola, D. O., Ibem, E. O., \& Ezema, I. C. (2018). Assessment Of Awareness and Adoption of Lean Practices in the Nigerian Building Industry. International Journal of Civil Engineering and Technology, 9(13), 1626-1640.

Bahidrah, S., \& Korkmaz, K. A. (2017). Barriers to the implementation of the 2030 Saudi Visions Sustainable Construction Objectives. Middle East Journal of Entrepreneurship, Leadership \& Sustainable Development, 1(1), 33.

Ballard, G. \& Kim, Y. (2007, July). Implementing Lean on Capital Projects. In proceedings of the 15th Annual Conference of the International Group for Lean Construction, IGLC, East Lansing, Michigan, USA, 88-97.

Ballard, G., Tommelein, I., Koskela, L., \& Howell, G. (2007). "Lean construction tools and techniques." Design and Construction, 1st Ed, R. Best, G.d Valence, Routledge, London, 251-279.

Bashir, A. M., Suresh, S., Oloke, D. A., Proverbs, D. G., \& Gameson, R. (2015). "Overcoming the challenges facing lean construction practice in the UK contracting organizations". International Journal of Architecture, Engineering and Construction, 4(1), 10-18.

CLMA.(2016). Construction Productivity in an Imbalanced Labor Market. In Construction Industry Resources, LLC. http://www.myclma.com/wpcontent/uploads/2016/06/Productivity White Paper_FINAL.pdf 
Dehdasht, G., and Zin, R. M. (2018). Barriers of Sustainable Lean Construction Implementation: Hierarchical Model. Int. J. of Adv. Res. 6 (8). 1094-1101].

Enshassi, A., Saleh, N., \& Mohamed, S. (2019). Barriers to the application of lean construction techniques concerning safety improvement in construction projects. International Journal of Construction Management, 1-17.

Jørgensen, B., \& Emmitt, S. (2008). Lost in transition: the transfer of lean manufacturing to construction. Engineering, Construction and Architectural Management, 15(4), 383-398.

Kanafani, J. (2015). Barriers to the implementation of lean thinking in the construction industry-the case of UAE, Masters dissertation, University of Leicester.

Kawish, S. E. (2017). "Identifying and Prioritizing Barriers and Overcoming Strategies in Implementing Lean Construction Principles and Methods within Transportation Projects". Mater of Science thesis, Michigan State University, Michigan.

Marhani, M. A., Jaapar, A., Bari, N. A. A., \& Zawawi, M. (2013). "Sustainability through lean construction approach: A literature review." Procedia-Social and Behavioral Sciences", 101, 9099.

McGraw Hill Construction, (2013). "Lean Construction - Leveraging Collaboration And Advanced Practices to Increase Project Efficiency (Smart Market Report)." Massachusetts: McGraw Hill Construction Research and Analytics.

Mok, K. Y., Shen, G. Q., \& Yang, J. (2015). Stakeholder management studies in mega construction projects: A review and future directions. International Journal of Project Management, 33(2), 446-457.

Mossman, A. (2009). “Why isn't the UK construction industry going lean with gusto?”. Lean Construction Journal, $24-36$

Noor, S. R. M., Yunus, R., Abdullah, A. H., Nagapan, S., Syahir, S. M., \& Mazlan, S. (2018). Insights into The Adoption of Lean Management in Industrialised Building System (IBS) Implementation: The Drivers and Challenges. International Journal of Engineering \& Technology, 7(3.23), 22-31.

Olamilokun, O. (2015). Investigating facilitators and barriers for adopting lean construction principles in the Nigerian building consulting firms. International Journal of Innovative Research \& Development, 4(12), 234-239.

Polat, G., \& Arditi, D. (2005). The JIT materials management system in developing countries. Construction Management and Economics, 23(7), 697-712.

Porwal, V., Fernández-Solís, J., Lavy, S. \& Rybkowski, Z. K. (2010). “Last Planner System Implementation Challenges", 18th Annual Conference of the International Group for Lean Construction, IGLC, Haifa, Israel, 548-556.

Sarhan, S. (2011). A strategy for overcoming barriers to the successful implementation of lean construction in the UK (Doctoral dissertation, University of Plymouth).

Sarhan, S., \& Fox, A. (2013). Barriers to implementing lean construction in the UK construction industry. The Built \& Human Environment Review. Volume 6.

Shang, G., \& Sui Pheng, L. (2014). Barriers to lean implementation in the construction industry in China. Journal of Technology Management in China, 9(2), 155-173.

Simonsen, R., Thyssen, M. H. \& Sander, D. (2014, June). 'Is Lean Construction Another Fading Management Concept?' In Proceedings of the 22nd Annual Conference of the International Group for Lean Construction. IGLC, Oslo, Norway, 85-96.

Wandahl, S. (2014). "Lean construction with or without lean-challenges of implementing lean construction." In Proceedings of the 22nd Annual Conference of the International Group for Lean Construction, IGLC, Oslo, 97-108.

Warcup, Robert D., "Successful Paths to Becoming a Lean Organization in the Construction Industry" (2015). All Graduate Theses and Dissertations. 4272, Utah State University. 